\title{
Sobre diversidade e unidade: dinâmicas locais e extralocais nas concepçóes do humanismo erasmiano, da Institutio principis christiani (1516) ao Ecclesiastae sive de ratione concionandi (1535)
}

Rui Luis Rodrigues*

\section{RESUMO}

Este artigo pretende analisar como as complexas relaçóes entre fatores de ordem local e extralocal aparecem no arcabouço do humanismo erasmiano. Propondo uma alternativa às leituras de Erasmo ora como cosmopolita, ora como um localista com atitudes ambíguas frente ao seu torrão natal, este texto intenta mostrar como o humanismo erasmiano foi o locus de uma concepçáo de sociedade que articulava esses elementos locais e extralocais num arranjo complexo, mas fundamentalmente retórico, a partir da ideia de respublica christiana, uma estrutura teológico-política de cujo caráter evanescente as últimas obras do humanista se mostram cada vez mais conscientes.

Palavras-chave: humanismo erasmiano; dinâmicas locais; dinâmicas extralocais; época moderna; respublica christiana.

\section{ABSTRACT}

This article aims to analyze how the complex relationships between local and extra-local dynamics appear in Erasmian humanism. Proposing an alternative to both readings of Erasmus as cosmopolitan, and as a localist with ambiguous attitudes towards his homeland, this paper endeavors to show how the Erasmian humanism was the locus of a conception of society that involved these local and extra-local elements in a complex but fundamentally rhetorical arrangement, based on the idea of respublica christiana: a theological-political structure with an evanescent character, of which the humanist's latter works are increasingly aware.

Keywords: Erasmian Humanism; Local Dynamics; Extra-Local Dynamics; Early Modernity; Respublica christiana.

DOI - http://dx.doi.org/10.1590/2237-101X0183403

Artigo recebido em 29 de junho de 2016 e aprovado para publicação em 5 de dezembro de 2016.

* Professor na Universidade Estadual de Campinas. Campinas - SP, Brasil. E-mail: ruiluis@msn.com. 


\section{RESUMEN}

Este artículo pretende analizar cómo las complejas relaciones entre factores de orden local y extra local aparecen en la estructura del humanismo erasmiano. Proponiendo una alternativa a las lecturas de Erasmo a veces como cosmopolita, a veces como un localista con actitudes ambiguas en relación a su tierra natal, este texto intenta mostrar cómo el humanismo erasmiano ha sido el locus de una concepción de sociedad que articulaba estos elementos locales y extra locales en un arreglo complejo pero fundamentalmente retórico, partiendo de la idea de respublica christiana y de una estructura teológico-política de cuyo carácter evanescente las últimas obras del humanista se revelan cada vez más conscientes.

Palabras clave: humanismo erasmiano; dinámicas locales; dinámicas extra locales; época moderna; respublica christiana.

As posturas adotadas pelo humanismo erasmiano diante daquilo a que chamaremos "local" — as dinâmicas regionais e suas diferentes configuraçôes: reinos, repúblicas, cidades livres dentro do império, comunas as mais diversas - e "extralocal" - as relações entre essas realidades regionais, numa época em que ainda não era possível falar em "nacionalidades" - foram, durante muito tempo, classificadas como exemplares dessa "ambiguidade" que parecia marcar o trabalho de Erasmo de Rotterdam. Em termos concretos, predominou na historiografia ao longo do século XX o olhar que enxergava em Erasmo o "cosmopolita", o homem que minimizava as realidades locais em prol de uma comunhão pan-europeia de matiz marcadamente intelectual: o Erasmo da respublica litterarum, a república das "bonae litterae" ou belas-letras. Tal é a compreensão do humanismo erasmiano que assinala o trabalho de Roland Bainton, Erasmo da Cristandade, publicado em 1969, num contexto em que as tensóes de um mundo dividido pela guerra fria eram contrabalançadas pelas esperanças de diálogo e de entendimento entre as religióes cristâs, introduzidas pelo Concílio Vaticano II. Mas é também, substancialmente, a concepção que informava o belo livro de Johan Huizinga sobre Erasmo, publicado em 1924, no contexto de uma Europa ainda dilacerada pelos horrores da Primeira Guerra Mundial. Neerlandês como Erasmo, Huizinga teve o mérito de frisar no humanista alguma inclinação "local", um certo apreço pelo torrão natal, sem perder de foco a imagem do erudito cosmopolita e avesso às querelas regionais. ${ }^{1}$

Essa leitura de Erasmo, efetivamente, poderia receber como epígrafe a frase polida com que, numa correspondência a Zwinglio, o humanista explicou sua recusa à cidadania de

1 BAINTON, Roland H. Erasmo da Cristandade. Lisboa: Fundação Calouste Gulbenkian, 1988; HUIZINGA, Johan. Erasmus and the Age of Reformation. Nova York: Harper Torchbooks, 1957. 
SOBRE DIVERSIDADE E UNIDADE: DINÂMICAS LOCAIS E EXTRALOCAIS NAS CONCEPÇÓES DO HUMANISMO ERASMIANO, DA INSTITUTIO PRINCIPIS CHRISTIANI (I 5 I 6 ) AO ECCLESIASTAE SIVE DE RATIONE CONCIONANDI (I 535 )

Rui Luis Rodrigues

Zurique, que lhe era oferecida: "Ser cidadão do mundo é o que desejo, compatriota de todos; ou, melhor ainda, um peregrino". ${ }^{2}$ Mas o avançar dos estudos erasmianos em fins do século XX não deixou de reconhecer, em frases como essa, o papel inequívoco desempenhado pela retórica: em suma, as afirmaçôes erasmianas não poderiam ser tomadas independentemente do contexto em que foram enunciadas, visto ser próprio da arte retórica não uma exposição objetiva, cartesiana, de motivaçôes, mas a subordinação da expressão literária às intençôes subjacentes ao discurso. ${ }^{3}$

Sensível à dimensão retórica e muito consciente das reviravoltas que o linguistic turn trouxe aos estudos históricos, James Tracy procurou dedicar ao humanismo erasmiano um outro olhar, capaz de captar, sob as vestes retóricas do cosmopolitismo, um Erasmo muito mais afeito às suas raízes neerlandesas: esse Erasmus of the Low Countries que, todavia - $\mathrm{e}$ aqui temos uma especificidade da análise de Tracy —, tinha com seu torráo natal uma relação problemática, conflituosa, assinalada por resistências e recusas. ${ }^{4}$

Do Erasmo civis mundi, "cidadão do mundo", ao Erasmo dos Países Baixos: a oscilação é radical, polar, ainda que não isenta de ambiguidades, como depreendemos tanto do antigo trabalho de Huizinga quanto da abordagem cuidadosamente gadameriana de Tracy. No entanto, nenhum desses trabalhos se dedicou a sondar adequadamente as razóes dessa aparente ambiguidade, dessa oscilação erasmiana entre o "local" e o "extralocal". Nossa hipótese é de que, quando confrontadas com a concepção erasmiana de sociedade e sua matriz estruturante, a noção de respublica christiana, essas ambiguidades se resolvem numa construção retórica de grande clareza e assinalada por elevado poder de convencimento. Ao mesmo tempo, no período que nos interessa, e que cobre aproximadamente os últimos 20 anos de vida do humanista, podemos constatar não apenas a maturação dessa construção retórica, mas também a percepção, por Erasmo, de seus limites — ainda que de forma incipiente.

\section{A concepção erasmiana de sociedade organológica e a respublica christiana}

Erasmo não apenas foi tributário de uma concepção organológica da sociedade, cuidadosa-

\footnotetext{
2 "Ego mundi civis esse cupio, communis omnium vel peregrinus magis". Erasmo a Zwinglio, in: Allen EE V: 1314 (CWE 9: 185; as abreviaçóes utilizadas neste texto estão relacionadas no final do artigo, após a Bibliografia. Todas as traduçôes constantes deste artigo são de minha responsabilidade, salvo indicação em contrário). Ver PAPY Jan. "Erasmus, Europe and Cosmopolitanism: The Humanist Image and Message in His Letters". In: PASINI, Enrico; ROSSI, Pietro B. (Ed.). Erasmo da Rotterdam e la cultura europea. Atti dell'Incontro di studi nel V centenario della laurea di Erasmo all'Università di Torino (Torino, 8-9 settembre 2006). Florença: SISMEL — Edizioni del Galluzzo, 2008, p. 27-42, aqui p. 38.

${ }^{3}$ MANSFIELD, Bruce. Phoenix of His Age: Interpretations of Erasmus, c. 1550-1750. Toronto: University of Toronto Press, 1979; ___ Man on his own: Interpretations of Erasmus, c. 1750-1920. Toronto: University of Toronto Press, 1992; CHOMARAT, Jacques. Grammaire et Rhetorique chez Erasme. Paris: Société d'Édition Les Belles Lettres, 2 v., 1981; HOFFMANN, Manfred. Rhetoric and Theology: The Hermeneutics of Erasmus. Toronto: University of Toronto Press, 1994.

${ }^{4}$ TRACY, James D. Erasmus of the Low Countries. Berkeley: University of California Press, 1996.
} 
SOBRE DIVERSIDADE E UNIDADE: DINÂMICAS LOCAIS E EXTRALOCAIS NAS CONCEPÇÓES DO HUMANISMO ERASMIANO, DA INSTITUTIO PRINCIPIS CHRISTIANI (I 5 I 6 ) AO ECCLESIASTAE SIVE DE RATIONE CONCIONANDI (I 535 )

Rui Luis Rodrigues

mente construída ao longo do medievo ocidental a partir de algumas tópicas da Antiguidade das quais o apólogo de Menênio Agrippa, narrado por Tito Lívio, é o exemplo mais emblemático; ele foi um entusiástico defensor dessa concepção e daquela que se tornou sua noção estruturante, a ideia da christianitas ou respublica christiana como ideal máximo de sociedade. ${ }^{5}$

Em breves palavras, podemos dizer que a noção de respublica christiana representou a cristianização da civitas romana, numa dinâmica onde a necessidade de civilizar o mundo, subjacente à lógica do orbis terrarum romanorum, identificou-se plenamente com a necessidade cristá de converter o mundo, de transformar o orbis terrarum romanorum em orbis christianum, oriunda desse universalismo do qual a fé cristã se mostrou desde cedo imbuída. Assim, esse movimento característico do Baixo Império romano, que foi a extensão da cidadania romana a todos os homens livres do império, independentemente de origem étnica, encontrou seu paralelo no convite que, na passagem do VI para o VII século, o papa Gregório Magno fez aos "bárbaros", no sentido de que se juntassem à sancta respublica. ${ }^{6}$

Uma vez que o universalismo cristão se sentiu à vontade nos limites da concepção romana de vida cívica, nada mais natural do que o estender, para a sociedade como um todo, daquela metáfora que Paulo, o apóstolo, havia empregado exclusivamente para a comunidade cristá: um corpo, dotado de muitos membros, onde a diversidade dos órgáos e de

\footnotetext{
${ }^{5}$ Sobre o apólogo de Menênio Agrippa, cf. TITO LÍVIO, Ab urbe condita libri, II, 32: "Placuit igitur oratorem ad plebem mitti Menenium Agrippam, facundum virum et quod inde oriundus erat plebi carum. Is intromissus in castra prisco illo dicendi et horrido modo nibil aliud quam hoc narrasse fertur: tempore quo in homine non ut nunc omnia in unum consentiant, sed singulis membris suum cuique consilium, suus sermo fuerit, indignatas reliquas partes sua cura, suo labore ac ministerio ventri omnia quaeri, ventrem in medio quietum nibil aliud quam datis voluptatibus frui; conspirasse inde ne manus ad os cibum ferrent, nec os acciperet datum, nec dentes quae acciperent conficerent. Hac ira, dum ventrem fame domare vellent, ipsa una membra totumque corpus ad extremam tabem venisse. Inde apparvisse ventris quoque haud segne ministerium esse, nec magis aliquam alere eum, reddentem in omnes corporis partes hunc quo vivimus vigemusque, divisum pariter in venas maturum confecto cibo sanguinem. Comparando hinc quam intestina corporis seditio similis esset irae plebis in patres, flexisse mentes hominum" "'Decidiu-se então enviar à plebe, como porta-voz, Menênio Agrippa, homem eloquente e bem quisto por ser oriundo da plebe. Uma vez introduzido no acampamento, pronunciou este apólogo naquele estilo de narrar um tanto áspero, típico dos antigos: 'Quando os membros do corpo não constituíam ainda, como agora, um todo harmônico, mas cada membro tinha sua própria linguagem e seu próprio modo de pensar, indignaram-se todas as demais partes por se estafarem a fim de satisfazer todas as necessidades do estômago, enquanto este permanecia tranquilamente no meio, tão somente gozando o prazer que lhe era dado. Concordaram, por esse motivo, que as mãos não levariam mais o alimento à boca, nem a boca aceitaria mais o que lhe fosse dado, nem os dentes consumiriam aquilo que recebessem. Enquanto, irados, acreditavam domesticar, pela fome, o estômago, chegaram à completa inaniçáo cada membro e o corpo todo. Então perceberam que o estômago tinha seu próprio mister e não permanecia inativo; nutria, tanto quanto era nutrido, e a todas as partes do corpo restituía, distribuído uniformemente pelas veias e enriquecido pelo alimento digerido, o sangue que nos dá vida e força'. Mostrando como a rebelião interna do corpo devia ser comparada à ira da plebe contra o Senado, Menênio mudou as mentes dos homens").

${ }^{6}$ AGNOLIN, Adone. Jesuitas e selvagens: A negociação da fé no encontro catequético-ritual americano-tupi (séculos XVI-XVIII). Sáo Paulo: Humanitas, 2007, p. 242-4; PAGDEN, Anthony. Señores de todo el mundo: Ideologías del Imperio en España, Inglaterra y Francia (En los siglos XVI, XVII y XVIII). Barcelona: Ediciones Península, 1997, p. 23-44 (aqui, especialmente p. 38-39).
} 
SOBRE DIVERSIDADE E UNIDADE: DINÂMICAS LOCAIS E EXTRALOCAIS NAS CONCEPÇÓES DO HUMANISMO ERASMIANO, DA INSTITUTIO PRINCIPIS CHRISTIANI (I 5 I 6 ) AO ECCLESIASTAE SIVE DE RATIONE CONCIONANDI (I 535 )

Rui Luis Rodrigues

suas funçóes era enfeixada na unidade do organismo. Essa imagem sequer era original: já se encontrava entranhada na consciência da república romana, como o mencionado apólogo de Menênio Agrippa deixa claro. Mas enquanto Paulo, judeu helenizado, fez da metáfora do organismo um uso eminentemente eclesiológico, a Igreja cristã, de seu lado, não hesitou em estendê-lo para a totalidade do corpo social. ${ }^{7}$

No plano ideológico, ao longo do período medieval as representaçóes da sociedade e da Igreja se sobrepunham sem se confundirem, numa dinâmica que também devia muito ao arcabouço teológico do pensamento ocidental: assim como na pessoa de Cristo as naturezas divina e humana estariam presentes, distintas, mas unidas, "sem confusão, sem mudança, sem divisão, sem separação" (como afirmava a fórmula do Concílio de Calcedônia, de 451), de igual modo a sociedade deveria ser marcada pela existência nítida de duas esferas, a sagrada e a secular, distintas mas não separadas. Essa concepção permitia a existência das magistraturas específicas, numa dinâmica onde não raro as funçôes do magistrado secular e do magistrado religioso encontravam-se investidas num mesmo indivíduo. Como consequência, o dualismo das esferas era atravessado pela impossibilidade de se pensar sociedade e fé cristã como realidades separadas. ${ }^{8}$

Essa sobreposição explica-nos por que Erasmo, ao deplorar as guerras entre os cristãos como fratricidas no comentário ao adágio Dulce bellum inexpertis, de 1515, fazia-o aplicando à sociedade europeia de seus dias aquela metáfora que Paulo reservara à Igreja:

Porventura é falso aquilo que São Paulo escreveu mais de uma vez: que a Igreja não é senão um único corpo formado pela junção de diversos membros, ligados a uma única cabeça, que é Cristo? Quem viu a vista lutar com a mão, ou o ventre com o pé? Existe harmonia entre todos os elementos, táo diferentes, que compóem esta unidade. [...] Acaso pode mais o liame da natureza num corpo condenado a perecer do que a união do espírito num corpo místico e imortal??

O comentário ao adágio Dulce bellum inexpertis ("A guerra é doce para os que a desconhecem") não tinha como interesse principal as questóes internas da Igreja, mas o grande problema da guerra e aquela que, para Erasmo, era a incompatibilidade visceral entre o cos-

\footnotetext{
${ }^{7} \mathrm{O}$ locus por excelência dessa perspectiva paulina é 1 Coríntios, 12, 12-27. Mas ver também Romanos 12, 4-5; Efésios 1, 22-23; 4, 4,16,25; 5, 23,30; Colossenses 2, 9-10,19 (o fato de Efésios e Colossenses serem provavelmente dêutero-paulinas não altera o fato de provirem do mesmo círculo ligado ao pensamento de Paulo). ${ }^{8}$ Insistem nessa característica da sociedade ocidental, onde as dimensôes religiosa e cívica se mostravam distintas, mas náo separadas, PRODI, Paolo. Uma história da justiça. Do pluralismo dos foros ao dualismo moderno entre consciência e direito. São Paulo: Martins Fontes, 2005, esp. p. 15-164 (capítulos I-III); SCHILLING, Heinz. Early modern european civilization and its political and cultural dynamism. The Menahem Stern Jerusalem Lectures. Lebanon: University Press of New England, 2008, p. 13-28.

${ }^{9}$ ERASMO. Dulce bellum inexpertis. In: ___. A guerra e a queixa da paz. Introdução, tradução do latim e notas de A. Guimarães Pinto. Lisboa: Ediçôes 70, 1999, p. 23-78, aqui p. 49-50.
} 
SOBRE DIVERSIDADE E UNIDADE: DINÂMICAS LOCAIS E EXTRALOCAIS NAS CONCEPÇÓES DO HUMANISMO ERASMIANO, DA INSTITUTIO PRINCIPIS CHRISTIANI (I 5 I 6 ) AO ECCLESIASTAE SIVE DE RATIONE CONCIONANDI (I 535 )

Rui Luis Rodrigues

tume guerreiro e a existência social: irmáos, membros de um mesmo corpo e unidos pelos mesmos vínculos sacramentais, não poderiam destruir-se reciprocamente. Noutro passo do mesmo texto, Erasmo afirma ser compreensível que os pagãos tivessem sido arrastados à insensatez da guerra; "mas a nós", escreve ele, "donde nos veio a ideia de um cristão desembainhar o ferro sanguino contra outro cristão? Se um cristão mata um irmão, chama-se a isso fratricídio. Mas um cristão está mais unido a outro cristão do que um qualquer irmão ao seu irmão". ${ }^{10}$

A perspectiva organológica controlava, portanto, a concepção erasmiana de sociedade; e o cimento dessa perspectiva era, para o humanista, o caráter cristão dessa república. É importante compreender que a própria ideia de uma "república das letras", a respublica litterarum da qual Erasmo falava, não existia à parte da respublica christiana, mas encontrava nela sua forma e seu conteúdo. ${ }^{11}$ Essa era a razão pela qual Erasmo increpava os humanistas ciceronianos de seu tempo; iludidos pela imitação de Cícero, esses humanistas esqueciam-se de sua própria fé e sacrificavam as especificidades cristãs a uma busca desesperada pelo estilo perfeito. ${ }^{12}$

\section{O humanismo erasmiano e as crises de seu tempo}

Tanto no comentário ao adágio Dulce bellum inexpertis como na Querela pacis, a "Queixa da paz", uma declamatio composta em 1517, Erasmo lidava com a mesma questão central: a multiplicação de conflitos entre os diferentes reinos europeus, que de fato atingira nas primeiras duas décadas do século XVI um índice alarmante. ${ }^{13}$ Essas obras foram marcadas pela percepção erasmiana de que as relações "extralocais", como diríamos nós, eram então altamente problemáticas e, na forma como eram conduzidas, contradiziam o modelo ideal de sociedade cristã.

Mas, a par desse problema de natureza "extralocal", Erasmo tinha também consciência de outra crise aguda: no nível local, no interior dessas sociedades que se compreendiam a partir do paradigma do corpo, nem sempre reinava a harmonia necessária; não apenas irmãos lutavam contra irmãos nas guerras entre diferentes reinos e repúblicas, mas no interior do

\footnotetext{
${ }^{10}$ ERASMO. Dulce bellum inexpertis, p. 47. A tradução portuguesa traz, neste ponto, "parricídio", o que é obviamente um lapso. Infelizmente não tive acesso ao texto latino deste adágio para traduzi-lo diretamente.

${ }^{11}$ Para uma reflexão sobre as relaçóes entre respublica litterarum e respublica christiana no humanismo erasmiano, ver RODRIGUES, Rui Luis. Entre o dito e o maldito: humanismo erasmiano, ortodoxia e heresia nos processos de confessionalização do Ocidente, 1530-1685. Tese (Doutorado) - FFLCH/USP, São Paulo, 2012, p. 103-31 ("O humanismo erasmiano entre a respublica litterarum e a respublica christiana").

${ }^{12}$ Para a controvérsia ciceroniana, o documento erasmiano fundamental é o colóquio Ciceronianus sive De optimo dicendi genere (Ciceroniano ou sobre o estilo latino ideal). $\mathrm{O}$ texto latino pode ser encontrado em $A S D$ I, 2: 599-710 e também em $L B$ I: 973-1026. Para uma boa tradução inglesa, ver $C W E$ 28: 342-448. O texto foi finalmente traduzido para o português pela professora Elaine C. Sartorelli. Ver ERASMO. Diálogo ciceroniano. Tradução e prefácio de Elaine C. Sartorelli. São Paulo: Editora Unesp, 2013.

${ }^{13}$ ERASMO. A queixa da paz. In: A guerra e a queixa da paz, op. cit., p. 79-133.
} 
SOBRE DIVERSIDADE E UNIDADE: DINÂMICAS LOCAIS E EXTRALOCAIS NAS CONCEPÇÓES DO HUMANISMO ERASMIANO, DA INSTITUTIO PRINCIPIS CHRISTIANI (I 5 I 6 ) AO ECCLESIASTAE SIVE DE RATIONE CONCIONANDI (I 535 )

Rui Luis Rodrigues

próprio organismo social os diferentes órgãos brigavam entre si.

Para compreendermos o pensamento erasmiano neste ponto, é preciso ter em mente que a concepção organológica da sociedade fundava-se na noção de que o corpo é constituído pela justaposição harmônica de órgãos necessariamente diferentes. Sem espaço para uma análise detalhada da evolução dessa metáfora ao longo do medievo tardio, podemos dizer, sinteticamente, que o corpus único da sociedade era compreendido como sendo composto por uma multiplicidade de corpora, de "corpos" que, conquanto diferentes, deveriam funcionar em harmonia no interior do corpus social único. Esses diferentes corpora não eram outra coisa senão os diferentes ordines ou "ordens" que constituíam o variegado tecido social europeu em fins do medievo e inícios da época moderna. Numa referência não exaustiva, mas bastante emblemática, Erasmo mencionou alguns desses ordines no Enchiridion militis christiani ou "Manual do soldado cristão", um escrito de 1501 que, reeditado em 1518 com novo e importantíssimo prefácio, ganhou a partir dessa reedição uma difusão absolutamente impressionante: ali, Erasmo fala da nobilitas, comportando diversos níveis; de homens ricos, pertencentes a diferentes estratos e integrando variadas guildas e corporações; de clérigos, também existindo numa multiplicidade nem sempre pacífica (Erasmo ocupa-se principalmente das querelas entre regulares, sobretudo mendicantes, e o clero secular); das diferentes magistraturas; e mesmo dos letrados, integrantes, eles também, de um ordo específico. ${ }^{14}$

James Tracy lê na postura erasmiana uma recusa a essa multiplicidade de ordines, por conta da intranquilidade que ela seria capaz de introduzir nas relações sociais. ${ }^{15}$ Para Tracy essa recusa viria das resistências de Erasmo à sociedade tipicamente neerlandesa: uma sociedade altamente corporativa, baseada em redes de relaçóes clientelares e onde um filho ilegítimo, como ele, teria sérios problemas para se integrar. Uma das manifestaçôes mais claras dessa recusa seria, ainda segundo Tracy, a seguinte declaração de Erasmo no Enchiridion:

Todos somos membros uns dos outros. Membros conectados constituem o corpo; a cabeça do corpo é Jesus Cristo, e Deus a cabeça de Cristo. O que é feito a ti, o que é feito a qualquer membro individual, para o bem ou para o mal, é feito a Cristo, é feito a Deus. Todas essas

\footnotetext{
${ }^{14}$ ERASMO. Enchiridion Militis Christiani. Coloniae: Apud Haeredes Arnoldi Birckmanni, 1563, p. $\mathrm{M}^{1 \mathrm{v}}$ $\mathrm{M}^{2}$. Para a impressionante difusão da edição de 1518 do Enchiridion, ver MCCONICA, James. Erasmus. In: THOMAS, Keith (Ed.). Renaissance Thinkers. Oxford/Nova York: Oxford University Press, 1993, p. 5-112, aqui p. 56-57. Para a matriz organológica de compreensão da sociedade, ver KANTOROWICZ, Ernst H. Os dois corpos do rei: um estudo sobre teologia política medieval. São Paulo: Companhia das Letras, 1998 (ed. original, 1957), esp. p. 125-169 (capítulo 5, “A realeza centrada no governo: corpus mysticum”) e p. 170-192 (capítulo 6, "Sobre continuidades e corporaçôes"). Para o impacto trazido sobre a compreensão organológica pela crescente complexidade do corpo social a partir de fins do medievo, ver RODRIGUES, Rui Luis, Entre o dito e o maldito, op. cit., p. 198-216.

${ }^{15}$ TRACY, James D. Erasmus of the Low Countries, op. cit., p. 80 (ver também ibidem, p. 17-38).
} 
SOBRE DIVERSIDADE E UNIDADE: DINÂMICAS LOCAIS E EXTRALOCAIS NAS CONCEPÇỐES DO HUMANISMO ERASMIANO, DA INSTITUTIO PRINCIPIS CHRISTIANI (I 5 I 6 ) AO ECCLESIASTAE SIVE DE RATIONE CONCIONANDI (I 535 )

Rui Luis Rodrigues

coisas são uma só: Deus, Cristo, corpo e membros. Entre cristãos não é apropriado o velho refrão "Cada um com seu igual”, nem aquele outro "A dessemelhança é a mãe das desavenças". Pois qual a finalidade de palavras de dissensão onde a unidade é tudo? ${ }^{36}$

Tracy acerta ao caracterizar a sociedade neerlandesa como profundamente corporativa e tecida por redes de relaçôes clientelares entre "vrienden en magen", "amigos e estômagos"; 17 mas erra ao ler em Erasmo uma defesa do individualismo atomístico contra essa sociedade corporativa. De fato, a importância dessas redes e a origem ilegítima de Erasmo representaram um problema para o humanista e se constituíram na principal razão de seu atrelamento, até o fim da vida, à ordem agostiniana, náo obstante as inúmeras dispensas de que gozava para vestir-se como secular e viver fora do convento; Erasmo, contudo, não respondeu a essa realidade pela recusa à sociedade corporativa, mas através do endosso dessa sociedade. Uma leitura atenta do contexto no Enchiridion em que se encontra a passagem já citada nos mostra que, ao contrário de exaltar os membros individuais do corpo de Cristo (e da sociedade), como pretende Tracy, o que importava para Erasmo era ressaltar a inserção do cristão, como indivíduo, em seu ordo e, através deste, na comunidade mais ampla da respublica. As dissensóes entre ordines são execradas por Erasmo, na medida em que representam um atentado contra essa unidade básica do corpo social; mas isso não é feito num tom de condenação global dos ordines e de defesa da mescla indiscriminada de todos os corpora, como pretende Tracy. Dirigindo-se de forma exemplar (não exaustiva) a diversos ordines de seu tempo, Erasmo não condena sua existência, mas procura assinalar criticamente as disputas entre eles e sublinhar a causa dessas querelas no esquecimento prático dos preceitos do evangelho. Na perspectiva erasmiana, não se proíbe a existência de distintos ordines no interior do corpo social, até porque a metáfora paulina do corpo depende radicalmente da ideia de pluralidade em unidade, ou seja, da coesão e do funcionamento harmônico de órgãos diferentes e possuidores de funçóes distintas. O que Erasmo rejeita é aquilo que podemos perceber como fruto da crescente complexidade da vida social: cada vez mais distintos e concretos, detentores de estatutos cada vez mais precisos, energizados por motivações cada vez mais variadas e não raro conflitantes, os corpora não conseguiam mais cooperar da forma harmônica exigida pela representação metafórica

\footnotetext{
16 "Omnes sumus inuicem membra. Membra cohaerentia constituunt corpus; corporis caput Iesus Christus; Christi caput Deus. Tibi fit, singulis fit, Christo fit, deo fit, quicquid unicuilibet membro fit seu bene seu male. Haec omnia unum sunt: deus, Christus, corpus et membra. Non recte inter Christianos locum habet illud: pares cum paribus et illud: dissimilitudo mater odii. Quorsum enim dissensionum uocabula, ubi tanta est unitas?" ERASMO, Enchiridion, pp. $\mathrm{M}^{1}-\mathrm{M}^{1 \mathrm{v}}$ (sigo aqui minha própria tradução, e não a oferecida por Tracy, que cita a passagem de forma abreviada e sem aduzir o texto original. Ver TRACY, James D. Erasmus of the Low Countries, op. cit., p. 38). Uma moderna tradução espanhola do Enchiridion pode ser encontrada em ERASMO. Enquiridion, Manual del cabalero cristiano. Tradução de Pedro Rodriguez Santidrian. Madri: Biblioteca de Autores Cristianos, 1995.
}

${ }_{17}^{17}$ TRACY, James D. Erasmus of the Low Countries, op. cit., p. 12-6. 
SOBRE DIVERSIDADE E UNIDADE: DINÂMICAS LOCAIS E EXTRALOCAIS NAS CONCEPÇÓES DO HUMANISMO ERASMIANO, DA INSTITUTIO PRINCIPIS CHRISTIANI (I 5 I 6 ) AO ECCLESIASTAE SIVE DE RATIONE CONCIONANDI (I 535 )

Rui Luis Rodrigues

da sociedade como organismo.

Ao condenar os ditos "Cada qual com seu igual" e "A dessemelhança é a mãe das desavenças", ${ }^{18}$ Erasmo não criticava o modelo corporativo de sociedade; sua crítica não se dirigia contra o fato de que qualquer ordo congrega semelhantes, mas contra os que se esqueciam de que, uma vez atraídos e congregados os iguais num ordo específico, este deveria servir à harmonia geral do corpo. O que Erasmo condenava era a atitude dos que ignoram que os seres humanos estão unidos por uma semelhança básica, para além de toda diferença superficial; inseridos como membros no mesmo corpo, todos são "próximos", ainda que ocupando posiçóes diferentes.

Erasmo não condenava, portanto, o paradigma organológico-corporativo da sociedade tardo-medieval e de inícios da época moderna; ao contrário, o projeto erasmiano tinha mais a ver com a manutençáo dessa estrutura comunal do que com um "individualismo" que ele, de fato, consideraria perigoso por representar a dissolução dos níveis corporativos de autoridade na auctoritas do príncipe. Para Erasmo, a existência desses níveis corporativos, com seus distintos foros e privilégios, representava a barreira mais efetiva contra a possibilidade, terrível para ele, da tirania.

\section{Do local ao extralocal, da política dos ordines à macropolítica}

Para a visão política que informava o paradigma organológico-corporativo, ao qual o humanismo erasmiano aderia, o príncipe aparecia como garante das liberdades possuídas por cada ordo e do necessário equilíbrio entre os ordines. O contrário do príncipe era o tirano: aquele que feria privilégios, usurpava liberdades e aos foros estabelecidos procurava impor sua própria vontade. Essa é a perspectiva que encontramos na Educação do príncipe cristão (Institutio principis christiani), texto de Erasmo, de 1516, pertencente ao gênero dos "espelhos de príncipe" e que foi escrito especialmente para Carlos de Gant, soberano dos Países Baixos desde 1515, herdeiro da Coroa espanhola (1516) e futuro imperador (1519). Composto quando a eleição imperial ainda não surgira no horizonte do futuro Carlos V, o texto de Erasmo enfatizava de forma recorrente essa necessidade de equilíbrio no interior do corpo social:

Uma vez que a república é uma espécie de corpo composto por vários membros, no número

${ }^{18} \mathrm{O}$ primeiro desses ditos tem origem ciceroniana: "Pares cum paribus facillime congregantur" ("Iguais com iguais são reunidos mais facilmente”). CÍCERO. De senectude, III. Já o segundo tem uma história bem mais complexa: sua origem mais provável é a referência presente no Eclesiástico 13, 18 (VL), "Omne animal diligit sibi simile et omnis homo proximum sibi" "Todo ser vivo ama o seu semelhante e todo homem, o seu próximo", BJ). Se a semelhança gera amor, a dessemelhança, por contraste, gera o ódio. Para o autor do Eclesiástico o preceito, conformando-se a uma regra natural, reflete a sabedoria divina e funciona positivamente na estruturação da sociedade, ao encorajar a frequentação mútua entre os que são da mesma condição. 
SOBRE DIVERSIDADE E UNIDADE: DINÂMICAS LOCAIS E EXTRALOCAIS NAS CONCEPÇÓES DO HUMANISMO ERASMIANO, DA INSTITUTIO PRINCIPIS CHRISTIANI (I 5 I 6 ) AO ECCLESIASTAE SIVE DE RATIONE CONCIONANDI (I 535 )

Rui Luis Rodrigues

dos quais está o próprio príncipe, ainda quando ele é exímio, será conveniente que use de moderaçáo para o bem de todos, de forma que um ou outro náo se tornem roliços e vigorosos enquanto os demais minguam. Pois se o príncipe se regozija e se alimenta dos infortúnios da república, nem é parte dela nem príncipe, mas antes um ladrão. ${ }^{19}$

É significativo que o texto destaque o lugar do príncipe entre os demais corpora estabelecidos ("in quorum numero sit et Princeps ipse”) e sublinhe seu caráter funcional. Essa maneira de encarar o ofício principesco é plenamente condizente com a dinâmica "polissinodal", respeitadora dos múltiplos foros de autoridade, que caracterizava a vida política em princípios da modernidade e não apenas nos Países Baixos. ${ }^{20}$ Era, obviamente, uma concepção de sociedade e de poder político onde a equanimidade pressupunha a desigualdade e a justiça residia não em tratar a todos de forma igual, mas em dar a cada um o tratamento devido a seu estatuto específico. O problema da desarmonia entre os ordines, passível de ser experimentado em qualquer república da cristandade, deveria ser contornado pela mediação da figura principesca; daí porque era absolutamente fundamental formar no príncipe uma disposição avessa à tirania.

Se por um lado era possível que um príncipe assim talhado cooperasse para evitar a anarquia oriunda da luta entre os diferentes ordines, coisa bem diversa era formar no príncipe uma disposição avessa ao outro dos grandes males do tempo, a guerra. Há inúmeros conselhos nesse sentido na Institutio principis christiani, a começar por uma educação que não desse ao jovem príncipe apenas grandes guerreiros como modelos. Mas, para o que diz respeito ao nosso tema, as relaçóes entre aspectos locais e extralocais no humanismo erasmiano, há uma outra percepção do humanista que nos interessa mais diretamente.

Para Erasmo, boa parte dos problemas de uma respublica tinha origem nas diferentes situações que levavam um príncipe a não dedicar atenção suficiente ao seu próprio reino. $\mathrm{O}$ bom governante, segundo Erasmo (que também nisso ecoava uma longeva tradição), devia

19 "Cum Respublica corpus quoddam sit ex uariis membris compactum, in quorum numero sit et Princeps ipse, licet eximium, ea moderatione conueniet uti, ut omnibus bene sit, non ut attenuatis caeteris unum aut alterum uegetum ac saginatum euadat. Quod si Princeps Reipublicae malis gaudet et alitur, neque pars est Reipublicae neque Princeps, sed praedo". ERASMO. Institutio principis christiani I, 87 (CWE 27: 237). Trabalhei com o texto latino disponível em: <http://agoraclass.fltr.ucl.ac.be/concordances/erasme_institutio_princ/texte. htm>. Acesso em: 27 jun. 2016. Para a tradução inglesa, ver $C W E$ 27: 203-88. Infelizmente não tive acesso à edição crítica do texto latino em ASD IV, 1: 136-219.

${ }^{20} \mathrm{O}$ estudo dessas dinâmicas deve muito aos trabalhos seminais de Otto Brunner, em especial seu Land and lordship: structures of governance in medieval Austria (Philadelphia: University of Pennsylvania Press, 1992; o original alemão é de 1939). Para sínteses importantes, ver OESTREICH, Gerhard. Problemas estruturais do absolutismo europeu. In: HESPANHA, Antonio Manuel (Org.). Poder e instituiçóes na Europa do Antigo Regime: Colectânea de Textos. Lisboa: Fundação Calouste Gulbenkian, 1984, p. 179-200; HESPANHA, António Manuel. As vésperas do Leviathan. Instituições e poder político. Portugal — Século XVII. Coimbra: Almedina, 1994; HESPANHA, António Manuel.. Para uma teoria da história institucional do Antigo Regime. In: HESPANHA, António Manuel. Poder e instituiçōes na Europa do Antigo Regime, op. cit., p. 7-89. 
SOBRE DIVERSIDADE E UNIDADE: DINÂMICAS LOCAIS E EXTRALOCAIS NAS CONCEPÇÓES DO HUMANISMO ERASMIANO, DA INSTITUTIO PRINCIPIS CHRISTIANI (I 5 I 6 ) AO ECCLESIASTAE SIVE DE RATIONE CONCIONANDI (I 535 )

Rui Luis Rodrigues

ser pai e pastor de seu povo; a tópica do príncipe como pai ressaltava uma noção importantíssima para a sociedade europeia tardo-medieval, a do afeto como vínculo fundamental entre soberano e povo.

O bom príncipe não deve ter outra atitude em relação a seus cidadãos que não seja a de um bom pai de família para com os de sua casa. Pois que mais é um reino senão uma grande família, e o que é um rei senão o pai de muitos?21

Aquele [o príncipe] está pronto a dar a própria vida por seus filhos; este [o tirano] não pensa senão em seu próprio ganho e conduz sua vida para atender a si mesmo, sem considerar o bemestar de seu povo. ${ }^{22}$

Já o emprego da tópica pastoral destacava o cuidado, e não a dominação, como característica principal do ofício principesco: o príncipe deveria ter em mente, segundo Erasmo, que “as palavras 'domínio', 'autoridade soberana', 'reino', 'majestade' e 'força' são termos pagãos e não cristãos; a autoridade soberana dos cristãos não é outra coisa senão administração, beneficência e cuidado". ${ }^{23}$ Essas imagens do príncipe como pai e pastor, para se concretizarem, exigiriam dele uma dedicação profunda à sua terra, de forma a conhecê-la intimamente:

Aplique-se [o príncipe] primeiramente em conhecer os territórios e cidades, sua localização, origem, características, instituições, costumes, leis, registros e privilégios. Ninguém pode curar o corpo se não está familiarizado com ele; ninguém apropriadamente cultiva um campo que não conhece. ${ }^{24}$

Muita coisa, no entanto, militava contra essa dedicação que o príncipe deveria devotar

21 "Bonus Princeps non alio animo debet esse in suo ciues, quam bonus paterfamilias in suos domesticos. Quid enim aliud est Regnum quam magna familia? Quid Rex nisi plurimorum pater?” ERASMO. Institutio principis christiani, I, 67 (CWE 27: 229).

22 "Ille cupit etiam uitam liberis suis impendere; hic nihil aliud spectat quam suum emolumentum, aut animo suo morem gerit, non suorum commodis consulit". ERASMO. Institutio principis christiani, I, 54 (CWE 27: 222). Ver ainda II, 9 (se há um título adequado para o príncipe, que seja "pater patriae", "pai da terra natal”; ver CWE 27: 249). Está subentendida, nesta figura, uma noção muito importante para as sociedades europeias tardo-medievais, a do amor, entendido náo sentimentalmente, mas implicando a lealdade filial dos súditos e, se necessário, a severidade punitiva do soberano, como vínculo efetivo entre os membros da sociedade. Ver a propósito I, 86 (CWE 27: 236) e III, 2 (CWE 27: 254).

23 "Cogitato semper, dominium, imperium, regnum, maiestatem, potentiam, Ethnicorum esse uocabula, non Christianorum. Christianum imperium nibil aliud esse quam administrationem, quam beneficentiam, quam custodiam". ERASMO. Institutio principis christiani, I, 79 (CWE 27: 233). Para a penetração da figura do príncipe como pastor do povo no imaginário medieval, e seu enraizamento em tópicas bíblicas e patrísticas, ver HUIZINGA, Johan. O outono da Idade Média. Estudo sobre as formas de vida e de pensamento dos séculos XIV e XV na França e nos Países Baixos. São Paulo: CosacNaify, 2010, p. 214.

24 "Studeat igitur in primis, regionum ac ciuitatum situm, originem, ingenium, instituta, consuetudines, leges, annales ac priuilegia cognoscere. Nemo potest mederi corpori, nisi cognito. Nemo recte colit agrum, quem non nouit". ERASMO. Institutio principis christiani, III, 1 (CWE 27: 253). 
SOBRE DIVERSIDADE E UNIDADE: DINÂMICAS LOCAIS E EXTRALOCAIS NAS CONCEPÇÓES DO HUMANISMO ERASMIANO, DA INSTITUTIO PRINCIPIS CHRISTIANI (I 5 I 6 ) AO ECCLESIASTAE SIVE DE RATIONE CONCIONANDI (I 535 )

Rui Luis Rodrigues

à república que lhe fora confiada. No caso de Carlos de Gant, o principal temor dos súditos neerlandeses, a darmos crédito a Erasmo, era a possibilidade de que o príncipe, herdeiro de um domínio que ia muito além dos Países Baixos, negligenciasse suas possessóes neerlandesas e fosse engolfado por interesses relacionados com territórios estrangeiros.

Essas preocupações, que já despontam na Institutio principis christiani, de maio de 1516, são retomadas por Erasmo na Querela pacis, publicada pelo editor Froben em dezembro de 1517. Com a liberdade possibilitada pelo gênero adotado - uma declamatio, onde o discurso é colocado nos lábios da Paz personificada - e por falar de forma mais geral, dirigindo-se a todos os príncipes cristãos, Erasmo pinta um quadro onde a paz perpétua seria fruto da ação de um príncipe paternal, que tivesse no bem-estar da república sua maior preocupação. Essa sociedade seria pacífica na exata medida em que o poder mudasse pouco de mãos; as alianças matrimoniais, em especial, eram criticadas por Erasmo, uma vez que entregavam a república nas mãos de estrangeiros que, muito provavelmente, reinariam como monarcas absenteístas e não cultivariam por ela verdadeiro apreço.

Para compreendermos aqui as opinióes de Erasmo, é importante lembrar que os Habsburgo se assenhorearam dos Países Baixos através do casamento entre o imperador Maximiliano e Maria, a Rica, filha de Carlos, o Temerário, duque da Borgonha; e que tanto Filipe, o Belo, filho de Maximiliano, quanto Carlos de Gant, filho de Filipe, reinaram sobre os Países Baixos como monarcas absenteístas. ${ }^{25}$ Finalmente, para evitar que a cobiça por territórios estrangeiros ofuscasse a razão do príncipe, seria interessante, segundo Erasmo, que ele evitasse até mesmo visitar outros territórios:

É próprio de um coração régio não dar ouvidos às paixóes privadas e tudo avaliar de acordo com a utilidade pública. A este fim, que o príncipe evite viagens a terras longínquas, ou melhor, que nunca queira cruzar as fronteiras do seu reino e que tenha presente o provérbio comprovado pelo longo consenso das idades: frons occipitio prior. ${ }^{26}$

O adágio aqui empregado por Erasmo, frons occipitio prior, é interessantíssimo. Literalmente, significa "A testa antes da nuca". A palavra prior, nele empregada, tem neste caso o sentido de "melior", "melhor"; assim, temos "Melhor a testa do que a nuca" ou "Antes a testa [é preferível a testa] do que a nuca". É um ditado que reaparece com várias conformaçôes em diferentes línguas europeias: "O olhar do dono engorda seu gado"; "O pé do dono é o melhor estrume para sua terra" etc. ${ }^{27} \mathrm{O}$ sentido geral é simples: melhor para uma república

${ }^{25}$ DE SCHEPPER, Hugo. The Burgundian-Habsburg Netherlands. In: BRADY JR., Thomas A.; OBERMAN, Heiko A.; TRACY, James D. (Ed.). Handbook of European History 1400-1600: Late Middle Ages, Renaissance and Reformation. V. I: Structures and Assertions. Leiden: E. J. Brill, 1994, p. 499-533.

${ }^{26}$ ERASMO. Querela pacis, p. 118.

${ }^{27}$ Ver BLAND, Robert. Proverbs, chiefly taken from the Adagia of Erasmus, with explanations; and further illustrated by corresponding examples from the Spanish, Italian, French \& English Languages. Londres: T. Egerton, 
SOBRE DIVERSIDADE E UNIDADE: DINÂMICAS LOCAIS E EXTRALOCAIS NAS CONCEPÇÓES DO HUMANISMO ERASMIANO, DA INSTITUTIO PRINCIPIS CHRISTIANI (I 5 I 6 ) AO ECCLESIASTAE SIVE DE RATIONE CONCIONANDI (I 535 )

Rui Luis Rodrigues

que o soberano lhe volte a testa, na forma de atenção continuada, do que a nuca (denotando interesse por outras terras).

A esta altura, podemos tentar uma síntese da solução proposta por Erasmo para esses dois problemas que percebia em seu tempo, as disputas entre os ordines e as contínuas guerras entre diferentes reinos, as tensōes "locais" e as tensóes "extralocais". Para ele, era preciso recordar a sociedade de seu fundamento, do fato de constituir, acima e para além de qualquer coisa, a respublica christiana. Que os diferentes ordines, portanto, sem prejuízo de suas especificidades e de seus direitos, se comportassem como órgãos de um mesmo corpo, funcionando harmoniosamente e de forma colaborativa (na melhor tradição do apólogo de Menênio Agrippa). Que os príncipes, garantes da paz na respublica, fossem cristãos verdadeiros e, como tais, combatessem esses dois monstros: no plano local, lutassem contra a sedução da tirania, contra o desejo de fortalecer seu poder às expensas dos demais foros de autoridade; no plano extralocal, esquecessem a cobiça e lutassem contra o desejo de dominar outras terras, fosse através de guerras, fosse através de alianças e casamentos (uma vez que boa parte das guerras tinha origem em direitos de sucessão pretensamente desrespeitados). $\mathrm{O}$ ataque erasmiano denunciava a expansão monárquica enquanto poderio avassalador, predominando não apenas sobre territórios alheios, mas também, na forma de tirania, sobre os privilégios longamente conservados pelos ordines; denunciava o caráter néscio da mudança dinástica baseada em alianças matrimoniais, que alçava desconhecidos ao trono e forçava-os à perene antipatia dos novos súditos. Era com isso em mente que Erasmo alertava seu próprio soberano, o príncipe Carlos, sobre qual deveria ser a natureza de sua preocupação básica. Na epístola que escreveu ao monarca em março de 1516, na qual dedicava a ele a Institutio principis christiani, o humanista afirmou, nos quadros de uma comparação entre Carlos e Alexandre, o grande:

Tu nasceste para um esplêndido império e estás destinado a herdar um ainda maior, de forma que, enquanto ele [Alexandre] precisou despender grandes esforços em invasóes, tu terás talvez que te esforçares para voluntariamente entregares parte de teus domínios, em vez de ampliá-los. ${ }^{28}$

$\mathrm{Na}$ concepção erasmiana, realidades locais e extralocais se relacionavam de forma complexa. A partir de uma moldura básica (a visão da sociedade como organismo), Erasmo enxergava na ideia de respublica christiana os contornos últimos dessa sociedade, sua norma

Military Library, Withehall, 1814, v. I, p. 43 (cf. p. 42-43 para o ensaio sobre o adágio).

${ }^{28}$ ERASMO. Ep 393 ao príncipe Carlos (Basileia, c. março de 1516), in: CWE 27: 204. Para o texto da epístola dedicatória, dependo apenas da tradução inglesa (CWE 27: 203-4), visto que a epístola não foi incluída na edição eletrônica preparada pela Universidade de Louvain. O trecho citado, na tradução inglesa: "You were born to a splendid empire and are destined to inherit one still greater, so that, while he had to expend great efforts on invasion, you will have perhaps to work to ensure that you can voluntarily hand over part of your dominions rather than seize more". 
SOBRE DIVERSIDADE E UNIDADE: DINÂMICAS LOCAIS E EXTRALOCAIS NAS CONCEPÇỐES DO HUMANISMO ERASMIANO, DA INSTITUTIO PRINCIPIS CHRISTIANI (I 5 I 6 ) AO ECCLESIASTAE SIVE DE RATIONE CONCIONANDI (I 535 )

Rui Luis Rodrigues

inegociável. Dentro desses limites, acomodados como devem estar os órgãos no interior do corpo humano, estáo os diferentes ordines. Em nível micro, cada república reedita a realidade da respublica christiana; assim como os ordines devem conviver em paz no seu interior, também as diferentes repúblicas devem conviver harmoniosamente no bojo da respublica christiana. Erasmo não foi o cultor de um cosmopolitismo de viés transnacional, pela simples razão de que essa perspectiva, dependente que era não apenas de um contexto de Estados nacionais estabelecidos, mas também da distinção nítida entre fatores políticos, culturais e religiosos, seria inviável em seus dias; tal concepção seria possível a partir do século XVIII, não antes disso. Mas Erasmo também não foi o "localista" ambíguo de que nos fala James Tracy, premido entre a valorização das tradiçôes comunais neerlandesas e a condenação de sua sociedade corporativa. O humanismo erasmiano foi o locus de uma concepção de sociedade que articulava esses elementos locais e extralocais num arranjo complexo, mas fundamentalmente retórico.

Era, todavia, um ideal de civilidade que começava a deixar de fazer sentido nos inícios da época moderna: época que, em graus que variavam de lugar para lugar, foi marcada por processos de centralizaçáo do poder, pelo esmagamento dos antigos foros e privilégios, pela expansão territorial e pelos conflitos decorrentes dessa expansão. A época de Erasmo foi assinalada por uma experiência significativa de "alargamento do mundo": o humanista tinha entre 23 e 26 anos em 1492, ano de sua ordenação ao sacerdócio católico e da chegada de Colombo à América. ${ }^{29}$ Mas esse "alargamento do mundo" foi acompanhado, também, por uma experiência igualmente complexa de "estreitamento" daquilo que, aos olhos de um humanista como ele, representava a principal parcela do mundo e era conhecido preferencialmente pelos termos intercambiáveis respublica christiana e christianitas: a experiência de um "estreitamento" da Europa. Sintomática, nesse sentido, é a declaração do velho Erasmo que aparece em seu último grande trabalho, um tratado sobre a pregação chamado Ecclesiastae sive de ratione concionandi libri quatuor ("Os Pregadores, ou Quatro livros sobre o método pelo qual se deve pregar”), publicado em 1535. Ali, Erasmo afirma:

Deus imortal! Quantas terras no mundo jazem abertas, nas quais ou a semente evangélica não foi semeada, ou foi semeada, porém o joio é mais numeroso do que o trigo! A menor parte do mundo é a Europa. ${ }^{30}$

Erasmo enxergava, aqui, uma Europa tornada mais estreita e reduzida a uma posição defensiva. Não era o continente que avançava pelo mundo no ímpeto colonizador que ele via;

\footnotetext{
${ }^{29}$ A dúvida sobre a idade efetiva do humanista se explica pela incerteza em torno de seu ano de nascimento (se 1466 ou 1469).

30 "Deum immortalem, quantum in orbe patet agrorum, in quibus aut nondum iactum est semen Euangelicum, aut ita iactum est, ut plus sit zizaniarum quam tritici. Orbis minima pars est Europa." ERASMO. Ecclesiastae sive de ratione concionandi libri quatuor. Basileae: Froben, 1535, p. 58 (grifos meus).
} 
SOBRE DIVERSIDADE E UNIDADE: DINÂMICAS LOCAIS E EXTRALOCAIS NAS CONCEPÇÓES DO HUMANISMO ERASMIANO, DA INSTITUTIO PRINCIPIS CHRISTIANI (I 5 I 6 ) AO ECCLESIASTAE SIVE DE RATIONE CONCIONANDI (I 535 )

Rui Luis Rodrigues

era o continente que fora grande, que sintetizara em si mesmo a proposta cristã de sociedade, mas que agora se achava premido pelos desafios externos, colocados pelo Orbis Novus (tantas terras, tantos povos aos quais lançar a semente cristã) e perplexo diante dos desafios internos (as guerras, as dissensóes, o cisma religioso). Era também com perplexidade que Erasmo, aparentemente, teria vislumbrado, no fim de sua vida, os limites da visão de mundo e de sociedade na qual fora formado e à qual dedicara seus melhores esforços; suas últimas obras indicam a percepção, ainda tênue, mas já assinalada com angústia, do lento desintegrar-se da noção de respublica christiana. ${ }^{31}$

$\mathrm{O}$ que Erasmo náo podia enxergar era aquilo que está mais claro para nós, que olhamos em retrospectiva. Essa Europa que parecia se encolher diante de um mundo ampliado, encolhia-se de fato para poder dominá-lo. A noção moderna de Europa formou-se num divórcio da antiga noção de christianitas, tão importante para o humanismo erasmiano: ${ }^{32}$ a fé cristã seria ofertada às novas sociedades desse mundo subitamente expandido, mas em um processo no qual à Europa caberia interpor, entre ela e essas novas sociedades, uma diferenciação fundamental; tais sociedades até deveriam tornar-se cristãs, mas jamais se tornariam parte da Europa. Erasmo não podia prever que a lógica da exploração colonial, que acoplara a si a própria missionação e em relação à qual ele desenvolvera uma atitude ambígua, levaria, ao fim de longo processo, à configuração de um status diferenciado para as sociedades coloniais. ${ }^{33}$ Nas configuraçóes das redes econômicas mundiais em formação,

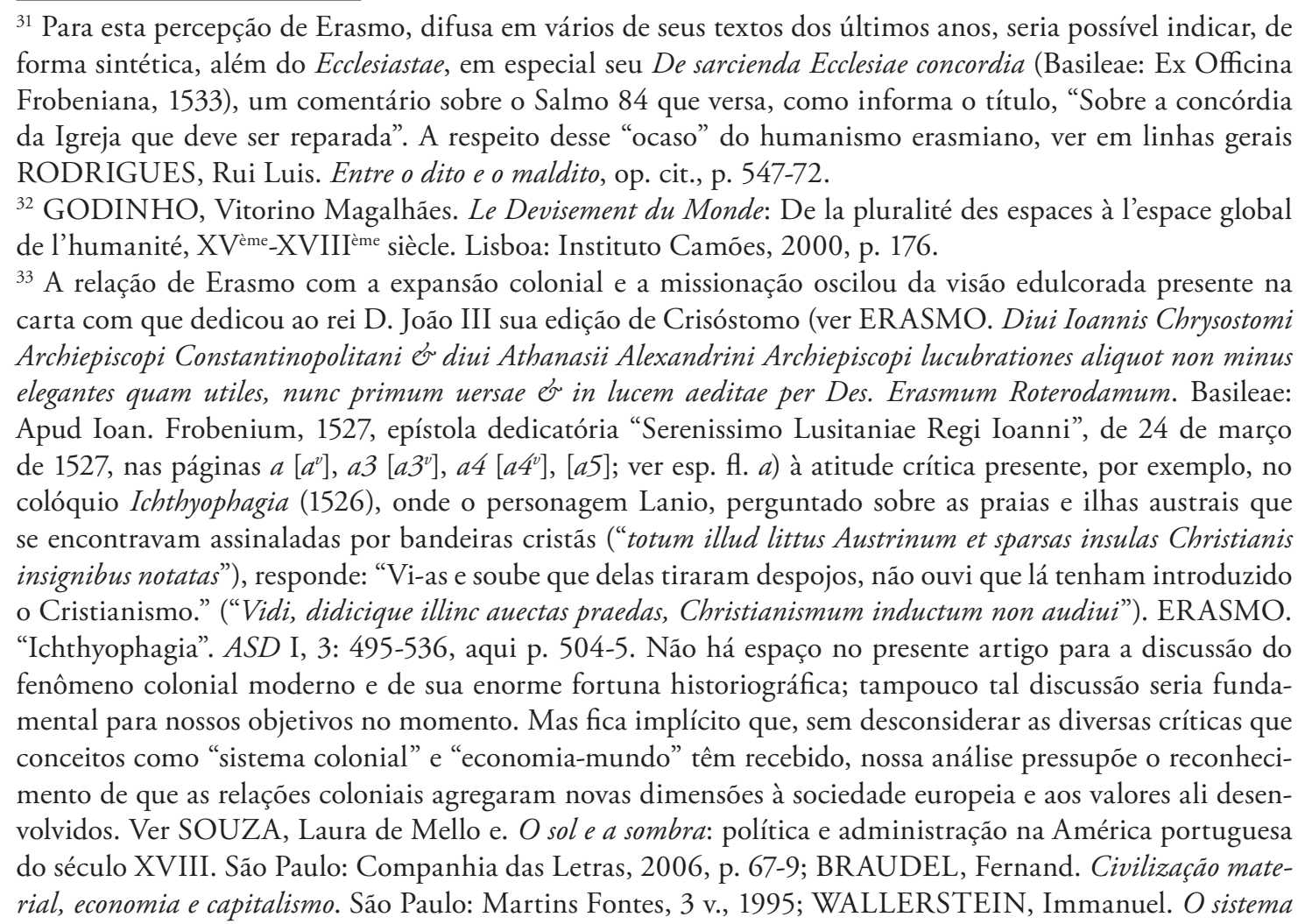


SOBRE DIVERSIDADE E UNIDADE: DINÂMICAS LOCAIS E EXTRALOCAIS NAS CONCEPÇÓES DO HUMANISMO ERASMIANO, DA INSTITUTIO PRINCIPIS CHRISTIANI (I 5 I 6 ) AO ECCLESIASTAE SIVE DE RATIONE CONCIONANDI (I 535 )

Rui Luis Rodrigues

a fé cristã continuaria por longo tempo como valor civilizacional, mas perderia seu estatuto de chave interpretativa da realidade. $\mathrm{O}$ mundo passaria a ser explicado, em grande parte, pelo comércio e suas dinâmicas, elementos de resto bastante alheios aos principais vetores do humanismo erasmiano.

\section{Bibliografia}

\section{Fontes}

ERASMO. Institutio principis christiani. Texto latino disponível em: $<$ http://agoraclass.fltr. ucl.ac.be/concordances/erasme_institutio_princ/texte.htm>. Acesso em: 27 jun. 2016. . Ep 393 ao príncipe Carlos (Basileia, c. março de 1516). In: CWE 27: 203-4.

. Dulce bellum inexpertis. In: . A guerra e a queixa da paz. Introdução, tradução do latim e notas de A. Guimarães Pinto. Lisboa: Ediçôes 70, 1999, p. 23-78.

. A queixa da paz. In: - A guerra e a queixa da paz. Introdução, tradução do latim e notas de A. Guimarães Pinto. Lisboa: Edições 70, 1999, p. 79-133.

. Enchiridion Militis Christiani. Coloniae: Apud Haeredes Arnoldi Birckmanni, 1563

. Enquiridion, Manual del cabalero cristiano. Tradução de Pedro Rodriguez Santidrian. Madri: Biblioteca de Autores Cristianos, 1995.

. Ichthyophagia. ASD I, 3: 495-536.

. Diálogo ciceroniano. Tradução e prefácio de Elaine C. Sartorelli. São Paulo: Editora Unesp, 2013.

- Diui Ioannis Chrysostomi Archiepiscopi Constantinopolitani \& diui Athanasii Alexandrini Archiepiscopi lucubrationes aliquot non minus elegantes quam utiles, nunc primum uersae \& in lucem aeditae per Des. Erasmum Roterodamum. Basileae: Apud Ioan. Frobenium, 1527.

. De sarcienda Ecclesiae concordia. Basileae: Ex Officina Frobeniana, 1533. . Ecclesiastae sive de ratione concionandi libri quatuor. Basileae: Froben, 1535.

\section{Bibliografia subsidiária}

AGNOLIN, Adone. Jesuitas e selvagens: A negociação da fé no encontro catequético-ritual americano-tupi (séculos XVI-XVIII). São Paulo: Humanitas, 2007.

BAINTON, Roland H. Erasmo da Cristandade. Lisboa: Fundação Calouste Gulbenkian, 
SOBRE DIVERSIDADE E UNIDADE: DINÂMICAS LOCAIS E EXTRALOCAIS NAS CONCEPÇỐES DO HUMANISMO ERASMIANO, DA INSTITUTIO PRINCIPIS CHRISTIANI (I 5 I 6 ) AO ECCLESIASTAE SIVE DE RATIONE CONCIONANDI (I 535 )

Rui Luis Rodrigues

1988.

BLAND, Robert. Proverbs, chiefly taken from the Adagia of Erasmus, with explanations; and further illustrated by corresponding examples from the Spanish, Italian, French of English Languages. Londres: T. Egerton, Military Library, Withehall, 1814. v. I

BRAUDEL, Fernand. Civilização material, economia e capitalismo. São Paulo: Martins Fontes, 3 v., 1995.

BRUNNER, Otto. Land and lordship: structures of governance in medieval Austria. Philadelphia: University of Pennsylvania Press, 1992.

CHOMARAT, Jacques. Grammaire et Rhetorique chez Erasme. Paris: Société d'Édition Les Belles Lettres, 2 v., 1981.

DE SCHEPPER, Hugo. The Burgundian-Habsburg Netherlands. In: BRADY JR., Thomas A.; OBERMAN, Heiko A. TRACY, James D. (Ed.). Handbook of European History 14001600: Late Middle Ages, Renaissance and Reformation. V. I: Structures and Assertions. Leiden: E. J. Brill, 1994, p. 499-533.

GODINHO, Vitorino Magalhães. Le Devisement du Monde: De la pluralité des espaces à l'espace global de l'humanité, XV'̀me-XVIII ${ }^{\text {ème }}$ siècle. Lisboa: Instituto Camóes, 2000.

HESPANHA, António Manuel. As vésperas do Leviathan. Instituiçóes e poder político. Portugal — Século XVII. Coimbra: Almedina, 1994.

- Para uma teoria da história institucional do Antigo Regime. In: - Poder e instituiçóes na Europa do Antigo Regime: colectânea de textos. Lisboa: Fundação Calouste Gulbenkian, 1984, p. 7-89.

HOFFMANN, Manfred. Rhetoric and Theology: The Hermeneutics of Erasmus. Toronto: University of Toronto Press, 1994.

HUIZINGA, Johan. O outono da Idade Média. Estudo sobre as formas de vida e de pensamento dos séculos XIV e XV na França e nos Países Baixos. São Paulo: CosacNaify, 2010.

. Erasmus and the Age of Reformation. Nova York: Harper Torchbooks, 1957.

KANTOROWICZ, Ernst H. Os dois corpos do rei: um estudo sobre teologia política medieval. São Paulo: Companhia das Letras, 1998.

MCCONICA, James. Erasmus. In: THOMAS, Keith (Ed.). Renaissance Thinkers. Oxford/ Noa York: Oxford University Press, 1993, p. 5-112.

MANSFIELD, Bruce. Phoenix of His Age: Interpretations of Erasmus, c. 1550-1750. Toronto: University of Toronto Press, 1979.

. Man on his own: Interpretations of Erasmus, c. 1750-1920. Toronto: University of Toronto Press, 1992.

OESTREICH, Gerhard. Problemas estruturais do absolutismo europeu. In: HESPANHA, Antonio Manuel (Org.). Poder e instituiçôes na Europa do Antigo Regime: colectânea de textos. 
SOBRE DIVERSIDADE E UNIDADE: DINÂMICAS LOCAIS E EXTRALOCAIS NAS CONCEPÇóES DO HUMANISMO ERASMIANO, DA INSTITUTIO PRINCIPIS CHRISTIANI (I 5 I 6) AO ECCLESIASTAE SIVE DE RATIONE CONCIONANDI (I 535 )

Lisboa: Fundação Calouste Gulbenkian, 1984, p. 179-200.

PAGDEN, Anthony. Señores de todo el mundo: Ideologías del Imperio en España, Inglaterra y Francia (En los siglos XVI, XVII y XVIII). Barcelona: Ediciones Península, 1997.

PAPY, Jan. Erasmus, Europe and Cosmopolitanism: The Humanist Image and Message in His Letters. In: PASINI, Enrico; ROSSI, Pietro B. (Ed.). Erasmo da Rotterdam e la cultura europea. Atti dell'Incontro di studi nel $V$ centenario della laurea di Erasmo all'Università di Torino (Torino, 8-9 settembre 2006). Florença: SISMEL - Edizioni del Galluzzo, 2008, p. $27-42$.

PRODI, Paolo. Uma história da justiça. Do pluralismo dos foros ao dualismo moderno entre consciência e direito. São Paulo: Martins Fontes, 2005.

RODRIGUES, Rui Luis. Entre o dito e o maldito: Humanismo erasmiano, ortodoxia e heresia nos processos de confessionalização do Ocidente, 1530-1685. Tese (Doutorado). São Paulo: FFLCH/USP, 2012.

SCHILLING, Heinz. Early modern european civilization and its political and cultural dynamism. The Menahem Stern Jerusalem Lectures. Lebanon: University Press of New England, 2008.

SOUZA, Laura de Mello e. O sol e a sombra: Política e administração na América portuguesa do século XVIII. São Paulo: Companhia das Letras, 2006.

TRACY, James D. Erasmus of the Low Countries. Berkeley: University of California Press, 1996.

WALLERSTEIN, Immanuel. O sistema mundial moderno. Porto: Afrontamento, 2 v., 1990.

\section{Abreviaçóes}

Allen EE P. S. ALLEN (Ed.). Opus epistolarum Desiderii Erasmi Roterodami denuo recongnitum et auctum per $P$. S. Allen. Oxford: Oxford University Press, 12 v., 1906-1965.

ASD Opera omnia Desiderii Erasmi Roterodami recognita et adnotatione critica instructa notisque illustrata. Amsterdä/Oxford: North Holland Publishing Company, 1969, vários volumes.

BJ Bíblia de Jerusalém. Nova edição, revista e ampliada. São Paulo: Paulus, 2002 (5. impressão, 2008).

CWE Collected Works of Erasmus. Toronto: University of Toronto Press, 1975 (vários volumes).

LB LECLERC, Jean (Ed.). Opera omnia Desiderii Erasmi Roterodami recognouit Ioannes Clericus. Leyden: 10 v., 1703-1706.

VL Vulgata Latina. Madri: BAC, 1991. 